nização e com muito, muito trabalho, tão eficientemente participaram na organização deste evento, os meus sinceros parabéns. Aos colegas e colaboradores, muito obrigada!

Este congresso, onde a cultura portuguesa foi uma aliada da Ciência, com um programa científico único, demonstrou claramente a importância da química orgânica para encontrar soluções inovadoras para muitos dos problemas da sociedade moderna. Reuniu académicos e industriais, jovens investigadores e alunos, de vários países, que partilharam as suas descobertas, constituindo um fórum de oportunidades e desafios.

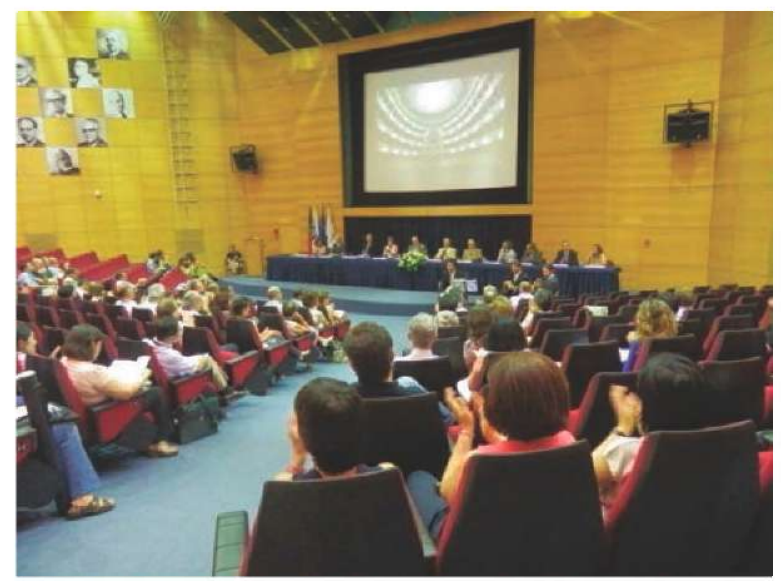

Visão geral do auditório

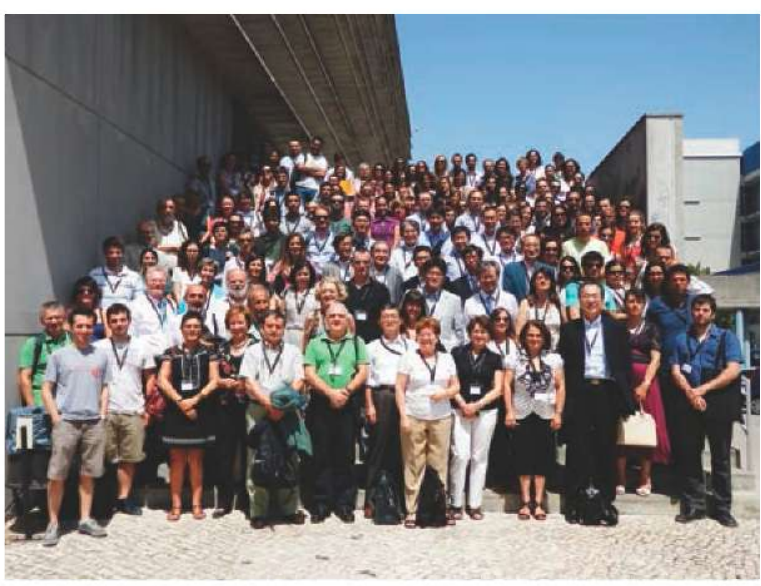

Fotografia de grupo
Amélia Pilar Rauter

(aprauter@fc.ul.pt)

Presidente da Comissão Organizadora

\title{
II Encontro em Técnicas de Caracterização e Análise Química
}

O II Encontro em Técnicas de Caracterização e Análise Química (II ETCAQ) decorreu no passado dia 8 de junho de 2012 na Universidade do Minho, no âmbito das actividades associadas ao Mestrado em Técnicas de Caracterização e Análise Química. Este Encontro teve como objetivo divulgar os avanços nas áreas das técnicas de caracterização e análise química e, também, dar a oportunidade aos alunos de conhecerem as atividades de empresas/laboratórios da área.

O programa do II ETCAQ focou várias áreas, nomeadamente a preparação de amostras, a caracterização de materiais e o sistema de gestão de qualidade, entre outros. Foram convidados

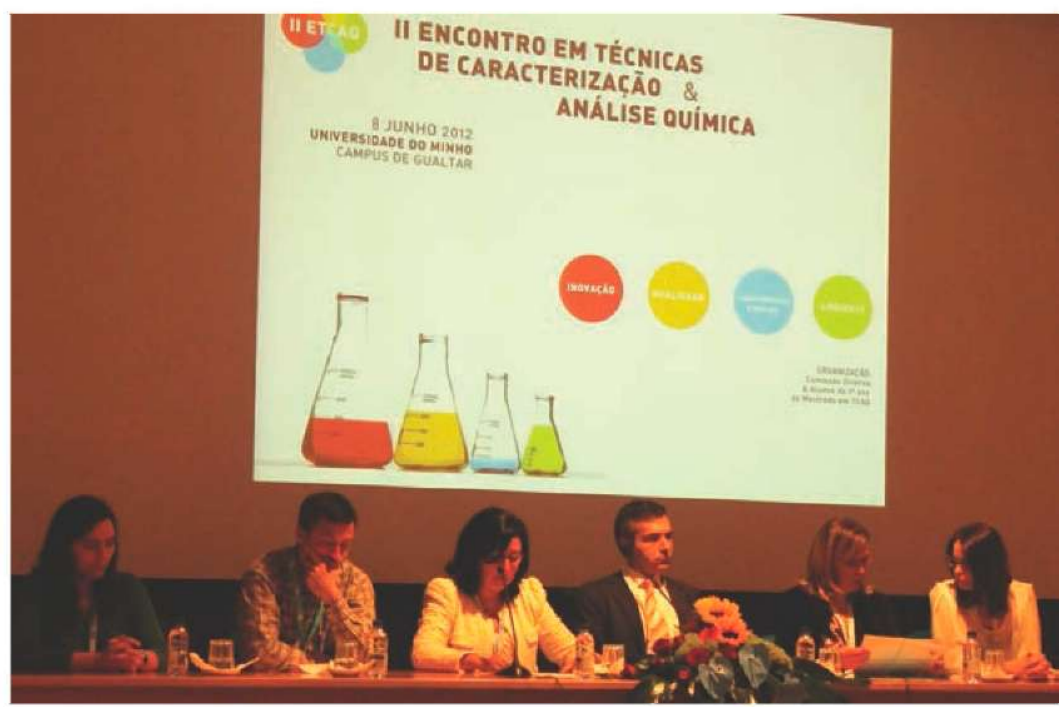

Sessão de abertura do II ETCAQ: da esquerda para a direita, Susana Costa (Comissão Organizadora), Luis Monteiro (Diretor do Departamento de Química), Dulce Geraldo (Comissão Organizadora), Vasco Teixeira (Pró-Reitor para a Investigação da Universidade do Minho), Maria João Queiróz (Diretora do Centro de Química) e Ana Paula Bettencourt (Comissão Organizadora) especialistas de universidades, assim como de empresas e laboratórios que desenvolvem atividade em áreas diversificadas no âmbito das metodologias e técnicas de caracterização e análise mais avançadas.

O II ETCAQ contou com 155 participantes e foram apresentadas $48 \mathrm{co}$ municações em painel provenientes de diversos laboratórios e empresas, institutos e universidades. De referir ainda que foi realizada uma mostra de equipamento e material científico ( 9 expositores), onde foram apresentadas inovações na área da instrumentação analítica.

O evento realizou-se no anfiteatro B1 do campus de Gualtar da Universidade do Minho e, após uma curta cerimónia de boas vindas a todos os participantes, foi possível assistir a um conjunto de palestras e comunicações orais convidadas de elevado nível científico, apresentadas por oradores convidados com percursos diferentes, tanto na área acadérnica como na empresarial, tendo sido a sua experiência profissional uma mais-valia para o Encontro. Houve 
duas sessőes de posters muito participadas que contribuiram para a troca de experiências entre os vários participantes. Na sessão de encerramento foram atribuídos dois prémios: o prémio para a melhor fotografia, atribuído entre as contribuições dos alunos do $2 .^{\circ}$ ano do Mestrado em Técnicas de Caracterização e Análise Química, e o prémio para a melhor comunicação em painel. Este evento contou com o apoio da Sociedade Portuguesa de Química e da Universidade do Minho e com o patrocínio de algumas empresas que gentilmente se associaram a esta organização.

Susana Costa (spc@quimica.uminho.pt) Comissão Organizadora do II ETCAQ na Universidade do Minho

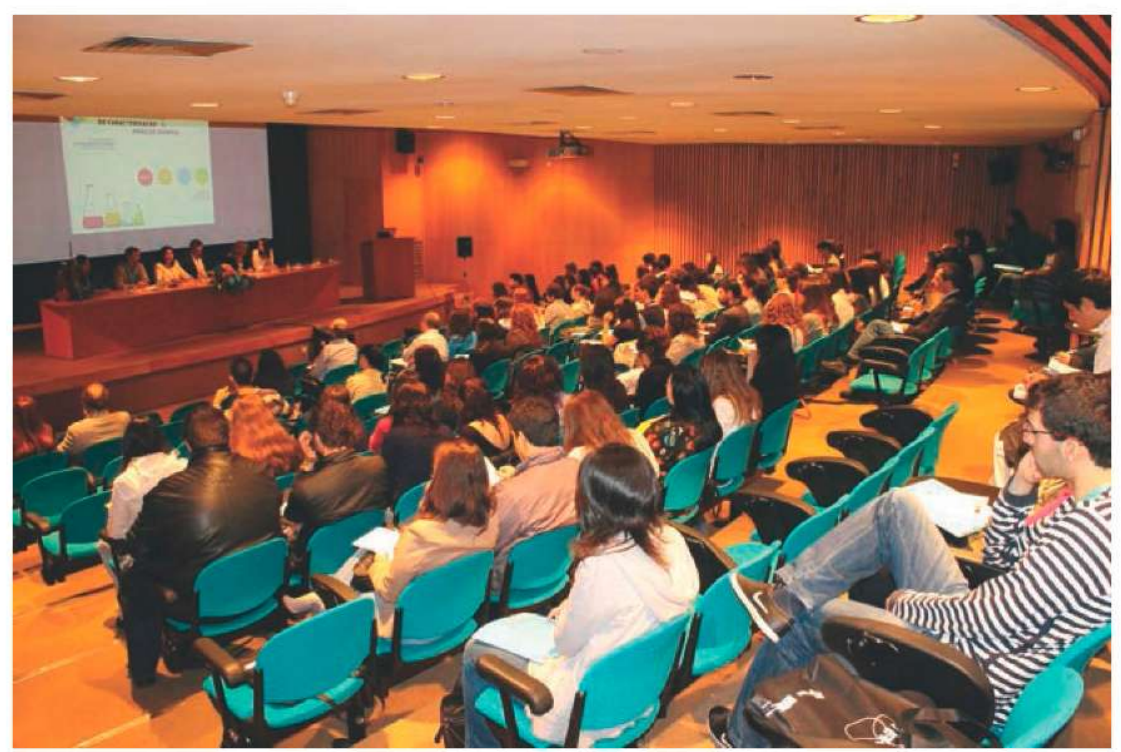

Perspetiva do Anfiteatro na sessão de abertura do II ETCAQ

\section{A Química no Mundo - Uma Retrospetiva sobre as Primeiras Jornadas de Química da FCUP}

final do passado mês de maio foi de celebração no Departamento de Química e Bioquímica (DQB) da Faculdade de Ciências da Universidade do Porto (FCUP). Nos dias 23 e 24 desse mês decorreram as Primeiras Jornadas da Química da FCUP (Figura 1), um evento que teve o apoio da Sociedade Portuguesa de Química. Subordinadas ao tema aglutinante "A Química no Mundo", estas jornadas trouxeram à atenção os vários domínios em que a Química surge como área científica central no conhecimento.

Nas palavras de Catarina Costa, aluna da licenciatura em Química e porta-voz da comissão organizadora do evento, "Quem frequenta ou frequentou a licenciatura em Química certamente já se interrogou qual é o papel da Química na sociedade. $\mathrm{Na}$ verdade, a maioria das pessoas não sabe realmente o que é a Química, logo torna-se imperativo tentar mostrar esta ciência, falar do que se faz ou se poderá fazer com ela, o que se aprende e a sua importância no mundo. Surgiu assim a ideia de promover um encontro entre as várias áreas da Química, num evento nunca antes realizado na Faculdade de Ciências da Universidade do Porto - as Jornadas da Química". Este encontro contou ainda com a colaboração de representantes de empresas diretamente relacionadas com a Química e com especialistas académicos das mais variadas áreas da Química.

A organização deste evento envolveu mais de uma dezena de estudantes de licenciatura e mestrado em Química. Um dos organizadores, Paul Costa, mencionou a importância deste tipo de eventos na promoção da Química no ambiente académico e até fora dele. Referiu também algumas dificuldades na produção de um evento desta magnitude, mas não deixou de elogiar os patrocinadores e todos os que apoiaram incansavelmente a organização destas jornadas.

A sessão de abertura do evento contou com a participação do Prof. Dr. António Teixeira Marques, Vice-Reitor da Comunicação, Imagem e Relações Internacionais da UP, do Prof. Dr. António Fernando da Silva, Diretor da FCUP, da Profa. Dra. Maria João Ramos, Professora Catedrática na FCUP e do Prof. Dr. Alexandre MagaIhães, Diretor da licenciatura em Química da FCUP. Todos foram unânimes em louvar o esforço dos organizadores do evento por todo o trabalho e tempo investidos na criação, estruturação e implementação de um projeto desta envergadura. Seguidamente, a assistência foi presenteada com uma belíssima palestra do Prof. Dr. José

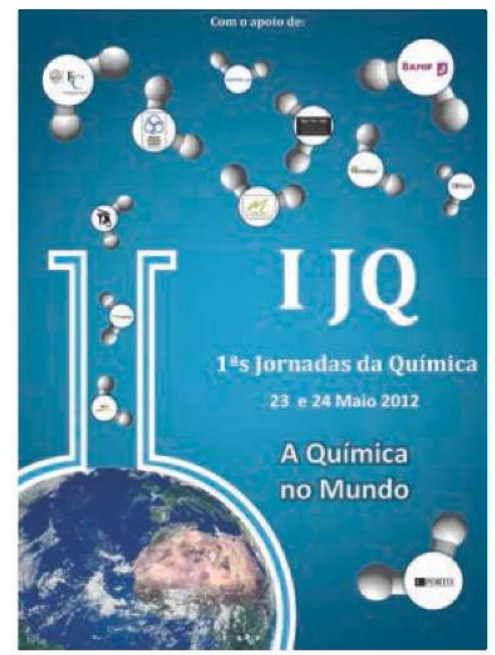

Figura 1 - Cartaz das Primeiras Jornadas de Química da FCUP

Veiga Simão, ex-Ministro da Educação e protagonista de uma reforma profunda no ensino universitário. $A$ palestra com o tema "A reforma "Veiga Simão" - 40 anos de Licenciatura em Química" trouxe à atenção a história do ensino académico das ciências físico-químicas e refletiu sobre as novas tendências de ensino académico em Portugal. Foi extremamente enriquecedor analisar como a lecionação académica da Química evoluiu nacionalmente. De seguida, o Dr. Nuno Palma, Investigador da empresa Bial abordou o tema " $A$ indústria Farmacêutica - Bial", onde o autor refletiu sobre a importância da Química Teórica e Computacional como meio de 